\section{A construção social da realidade e os operadores jornalísticos}

\section{RESUMO}

Este trabalho tem como objetivo contribuir para a discussão do jornalismo como um lugar que participa diariamente na construção social da realidade. Para tanto tomamos por base a teoria da enunciação e a enunciação jornalística, procurando mostrar suas especificidades. Consideramos que na construção do real o jornalista mobiliza diariamente uma série de operações enunciativas. No entanto, com base numa pesquisa que realizamos (Pereira Junior, 2002) categorizamos as que consideramos as mais presentes no dia-a-dia da redação: operadores de atualidade, operadores de objetividade, operadores de interpelação, operadores de leitura e operadores didáticos.

\section{ABSTRACT}

This text intends to contribute to the ongoing discussion about the social role of journalism, arguing that it is a place which contributes daily to the social construction of reality. The author takes as his departure point the theory of enontiation and then applies it towards the categorization of the operations which the journalistic enontiation performs daily. A practical research done previously by the author finds that the operations which appear most frequently in journalistic activities are those which deal with the notions of factuality, objectivity, interpelation, reading and teaching.

\section{PALAVRAS-CHAVE (KEY WORDS)}

- Jornalismo (Journalism)

- "Teorias" (Theories)

- Operadores jornalísticos (Journalistic operators)

\section{Prof. Dr. Alfredo Vizeu}

Chefe do Departamento de Comunicação Social da UFPe

\section{A força do jornalismo}

DE UMA MANEIRA GERAL, podemos resumir as definições de jornalismo e notícia a partir de dois grandes grupos: os que defendem a notícia como um espelho da realidade e aqueles que concebem a notícia como uma construção social da realidade.

Num estudo clássico sobre a produção da notícia, Tuchman (1983) tendo como pressuposto a concepção sociológica dos atores sociais argumenta que, por um lado, a sociedade ajuda a formar a consciência e, por outro, mediante uma apreensão intencional dos fenômenos do mundo social compartilhado - mediante seu trabalho efetivo -, os homens e as mulheres constroem e constituem os fenômenos sociais coletivamente.

Segundo a autora, cada uma destas perspectivas ao aturem sobre os atores sociais determinam uma abordagem diferente da notícia. Já a idéia da notícia como um espelho da realidade corresponderia à concepção tradicional das notícias. Este ponto de vista defende a "objetividade" como um elemento chave da atividade jornalística. Dentro desta concepção, o máximo que se admite é a possibilidade de que as notícias reflitam o ponto de vista do jornalista (STAMM, 1976).

Tuchman defende que a notícia não espelha a realidade. Para a autora, a notícia ajuda a constituí-la como um fenômeno social compartilhado, uma vez que no processo de definir um acontecimento a notícia define e dá forma a este acontecimento. $\mathrm{Ou}$ seja, a notícia está permanentemente definindo e redefinindo, constituindo e reconstituindo fenômenos sociais. 
No Brasil, a concepção de que o jornalismo é um simples espelho da realidade ainda encontra um grande espaço nas redações, em algumas faculdades de Jornalismo e em pesquisas que vêem no jornalismo um simples reprodutor do real.

Autores como Luiz Amaral (1987) e Juarez Bahia (1990) definem a atividade jornalística como uma simples técnica, reduzindo-a a uma operação meramente mecânica de meia dúzia de regras como já nos referimos anteriormente.

Em oposição a essa visão mecanicista temos um campo de estudos ainda em construção que procura entender o jornalismo como uma forma de conhecimento (MEDITSCH, 1992). Grosso modo, o jornalista não seria alguém que comunica a outrem o conhecimento da realidade, mas também quem o produz e o reproduz.

Entendemos que a definição do jornalismo como um conjunto de técnicas especiais é reducionista e não consegue compreender o campo jornalístico como "lugar estratégico" de produção e construção do real. A idéia de que o jornalista é um mero reprodutor de fatos e que bastaria que ele acionasse de uma forma correta um conjunto de regras para realizar um bom trabalho, um bom texto, não corresponde à realidade.

No dia-a-dia de sua atividade, o jornalista é servido pela língua, códigos e regras do campo das linguagens, para, no trabalho da enunciação produzir discursos. Em outras palavras, o jornalismo tem uma dimensão simbólica (FAUSTO NETO, 1991).

Partindo do pressuposto de que o ato de discursar resulta do contato do jornalista com o campo do código, é possível se afirmar que o "ato jornalístico" mais do que trabalhar com "regras", "leis" ou "dicas", estrutura-se a partir de dois momentos estratégicos: operação e construção, cujas regras são pensadas, independentes do sujeito, pois quando ele as aciona, elas já estão estruturadas no campo da linguagem.

\section{O discurso jornalístico}

Na elaboração do seu texto, o jornalista vai utilizar procedimentos de seleção e combinação, mediante unidades que articuladas, vão se transformar em mensagens, ou de um modo mais abrangente, em discursos sociais. Este trabalho de operação não se dá apenas no campo restrito do código, uma vez que o sujeito se defronta com outros códigos - ou outros discursos - de que empresta também para a constituição de suas unidades discursivas. Do trabalho de operar com vários discursos resultam construções, que, no jargão jornalístico, podem ser chamadas de notícias.

Este trabalho do sujeito, a partir e através do outro, não é algo mecânico e não pode repousar sobre a idéia de que do simples recurso à língua resultaria a transparências das mensagens. O grau de nomeação das coisas pelas palavras não se dá apenas pelo recurso da justaposição, mas por algo que decorre do investimento do trabalho da enunciação, isto é pelo sujeito (BENVENISTE, 1995).

A enunciação é uma espécie de tomada de posição, a instância que estrutura o valor do dito - as mensagens que ganham formas de matérias, segundo economias específicas a cada sistema e/ou suporte (veículo) de comunicação e que produzem dimensões classificatórias da realidade.

Como mostrou Benveniste, o único modo de fazer o discurso funcionar é pela intervenção do sujeito, que nele investe sua subjetividade: "A enunciação é este colocar em funcionamento a língua por um ato individual de utilização" (1989, p.82).

No entanto, no ato enunciativo, o sujeito não constitui apenas a si, sujeito locutor, mas também o sujeito-alocutário, isto é, define não só a posição $e u$, mas também a do tu: "...ele implanta o outro diante de si, qualquer que seja o grau de presença que ele atribua a este outro. Toda a enunciação é, explicita ou implicitamente, uma alocução, ela postula um alocutário" (BENVENISTE, 1989, p.84)

Para o autor, o que em geral caracteriza a enunciação é a acentuação da relação discursiva com o parceiro. $\mathrm{Na}$ realização do 
seu estudo sobre o aparelho formal da enunciação, ele tomou como os principais pontos de partida os sistemas pronominal e verbal do francês (BENVENISTE, 1995, p.247-283).

$\mathrm{Na}$ descrição do sistema pronominal, o autor distingue os pronomes da pessoa $\left(1^{\mathrm{a}}\right.$ e $\left.2^{\mathrm{a}}\right)$ dos pronomes da não pessoa $\left(3^{\mathrm{a}}\right)$. Os primeiros designam os interlocutores, os sujeitos envolvidos na interlocução(eu, tu, você; nós, vós, vocês); os últimos designam os referentes (seres do mundo extralingüístico de que se fala) e, assim, não devem ser colocados na mesma classe dos primeiros.

Deste modo, as pessoas e o tempo do enunciado são referenciados relativamente a essa situação de enunciação; assim, o enunciado possui o valor elocutório que ele mostra através da sua enunciação.

Em seu livro Quando Dizer é Fazer, Austin (1990) distingue com precisão três atividades complementares na enunciação. Proferir um enunciado é ao mesmo tempo: -realizar um ato locutório, produzir uma série de sons dotada de um sentido numa língua;

-realizar um ato ilocutório, produzir um enunciado ao qual se vincula convencionalmente através do próprio dizer uma força No telejornalismo é muito comum os editores trabalharem com atos ilocutórios ao interpelar a audiência. Por exemplo: Confira...; -realizar uma ação perlocutória, isto é , provocar efeitos por intermédio da palavra (por exemplo, pode-se fazer uma pergunta - ato ilocutório - para interromper alguém, para embaraçá-lo, para mostrar que se está ali, etc.). O campo do perlocutório sai do contexto propriamente lingüístico.

Grosso modo, Austin mostra que é impossível encontrar enunciações sem valor perfomativo que só descrevessem o mundo. Até um enunciado que parece puramente descritivo como está chovendo, coloca-nos diante de uma realidade nova, realiza também uma ação, no caso, um ato de afirmação.

Dessa forma, o discurso jornalístico é produzido com base no concurso e do efeito daquilo que lhe ofertam outros códigos, isto é, outras vozes e múltiplas polifonias provenientes de outros campos culturais ou que deles são tomadas por empréstimo: vozes deontológicas - que dão conta de um certo fazer discursivo; as vozes da divisão social do trabalho inerente ao jornalismo; as vozes da pedagogia -cada vez mais o discurso jornalístico se insinua como uma espécie de saber explicativo dos processos sociais.

\section{O jornalismo e as operações enun- ciativas}

As formas da enunciação jornalística são marcadas por processos de raciocínio ou cadeias de razões que visam determinados efeitos de reconhecimento (apreensão, compreensão pela audiência) e podem restringir-se ao anúncio, a descrição, a argumentação, a demonstração e a persuasão.

I- Anunciar: dizer o que aconteceu ou vai acontecer; dizer o que alguém disse, subtendendo a relevância do dito;

II- Descrever: relatar as etapas de um fato, com suas circunstâncias; os passos de um personagem, com seus comportamentos, atitudes, declarações ou proposições ou o quadro de uma situação, com dos diversos aspectos envolvidos;

III- Demonstrar: provar a relevância, validade ou veracidade do que foi anunciado ou descrito;

IV-Argumentar: orientar inferências a partir do que foi dito ou realizado (é o que acontece, comumente, na abertura das matérias no telejornalismo);

V- Persuadir: buscar convencer o outro da importância e da veracidade do relato, utilizando-se, no caso da sedução, apelos muitos comuns (por exemplo, na abrir a cabeça de uma matéria dizendo: Violência na zona norte de Vitória.)

Dentro desse contexto, com base num trabalho que desenvolvemos (PEREIRA JUNIOR,2002) categorizamos cinco operações enunciativas mobilizadas pelos jornalistas diariamente, de forma consciente ou inconsciente, na produção dos textos: operadores de atualidade, operadores de objetividade, 
operadores de interpelação, operadores de leitura e operadores didáticos.

As operações enunciativas correspondem a determinadas operações lógico-semânticas e/ou pragmáticas que o enunciador propõe que o co-enunciador refaça para recriar o universo de discurso em jogo no processo comunciativo.

Os operadores de atualidade: o jornalismo, em particular, o gênero telejornal, é, na essência, o discurso da atualidade. Não da atualidade cronológica, já que entre o momento do acontecimento do fato e a notícia, temos um interregno mediado pelo telejornal, mas da atualidade do noticiário televisivo. Mesmo um evento transmitido ao vivo, em tempo real, se submete ao tempo e à formatação do telejornal: há um recorte sobre a realidade (pelo plano da tomada, pela forma de enquadramento, etc).

Como observa Machado (2000, p.104): “o telejornal é, antes de mais nada, o lugar onde se dão atos de enunciação a respeito dos eventos". Isto é, sujeitos falantes diversos se sucedem, se revezam, se contrapõem uns aos outros, praticando atos de fala que se colocam nitidamente como o seu discurso com relação aos fatos relatados.

Por isso, compartilhamos da opinião de Requena (1989), para quem é de fundamental importância a adoção de uma enunciação subjetiva, que garanta a presença dominante no discurso do presente da enunciação. Se o presente absoluto do fato é impossível, não importa, o discurso se organizará sobre o presente da enunciação do fato, este sim absoluto: o presente do próprio ato comunicativo. Exemplo:

\section{(E1) Loc./apres. : \\ MAU TEMPO SUSPENDE \\ TRABALHOS DE RETIRADA DE \\ ÁGUA DE NAVIO. / A \\ EMBARCAÇÃO ESTÁ, HÁ TRÊS \\ ANOS, PARADA EM \\ ALTO-MAR. / AGORA, CORRE \\ RISCO DE AFUNDAR E \\ PROVOCAR UM ACIDENTE \\ ECOLÓGICO NO LITORAL DA}

-VT-navio/destino 29/05/2000 (ESTV2 $\left.{ }^{a} E D\right)$
GRANDE VITÓRIA. / / /

\section{/ / / / / / RODA VT / / / / / / /}

No enunciado acima as conjugações verbais estão no presente do indicativo: suspende e corre. O enunciador procurou trabalhar o tempo verbal no sentido da atualidade do discurso. Há, de certa forma, um apagamento do tempo em que o fato ocorreu para um presente presentificado, a temporalidade do noticiário televisivo.

$\mathrm{O}$ que o jornalista, produtor-enunciador do discurso, procurou fazer foi com que os verbos no presente do indicativo coincidissem com o momento da enunciação, isto é, com a leitura do texto pelo loc./apres. $\mathrm{Na}$ prática, uma descontextualização do fato e seu enquadramento no tempo do telejornal, o presente da enunciação.

Os operadores de objetividade: estão intimamente relacionados com os operadores anteriores uma vez que uma das principais preocupações do jornalismo é tentar reproduzir o fato tal como ocorreu. É garantir que o que está sendo relatado é verdadeiro: o culto da objetividade e da independência do jornalismo.

Daí, a noção de jornal como espelho da realidade, como transportador do real. Daí também a noção do jornal ou do jornalista como um ser que paira sobre os fatos e tudo pode transmitir sem reelaboração nem constrangimentos. Exemplo:

\section{-VT-passeata/servidores 29/05/2000}

(E6) Loc./apres. :

SERVIDORES DO ESTADO

FAZEM PASSEATA NO CENTRO

DE VITÓRIA. / RECLAMAM QUE

O GOVERNO NÃO ATENDE ÀS

REIVINDICAÇÕES. / A

MANIFESTAÇÃO DUROU QUASE

DUAS HORAS E TUMULTOU

AINDA MAIS O TRÂNSITO. / / /

/ / / / / / RODA VT / / / / / / /

No enunciado, observamos a tentativa de simulação de objetividade com o discurso indireto. O objetivo é dar a impressão que o telejornal "reproduz" a realidade sob pena 
de a notícia parecer falsa, o que comprometeria sua credibilidade. Nesse sentido, o poder do discurso do noticiário está na sua capacidade de construir a ilusão da realidade, isso porque, na maioria das vezes, matériaprima usada, a reportagem ou a informação que chega à redação já é o resultado de uma cadeia enunciativa de dimensão indefinida.

A objetividade é de fundamental importância para o jornalismo, representa um dogma central do campo, porque está intimamente ligada a um fator inerente ao discurso jornalístico que é a credibilidade. Caso o telespectador (co-enunciador) não acredite mais no que o noticiário televisivo está dizendo, é rompido um contrato de cumplicidade entre o jornal e o seu interlocutor.

Operadores de interpelação: o noticiário televisivo, em especial, mostra-nos várias maneiras pelas quais a gramática da produção procura construir um vínculo ativo com a recepção. Os telejornais analisados procuram estabelecer com seus usuários determinadas ações, que classificamos como ações de captura, construídas semanticamente pelos jornalistas, que presentificam a audiência no interior do próprio telejornal. Exemplo:

-VT-tabela/jogos hoje 17/05/2000

(E11) Loc./apres. :

SEIS JOGOS HOJE PELA

SEGUNDA RODADA DO

RETURNO. / DUAS PARTIDAS

FORAM À TARDE. / O SANTA

MARIA GANHOU DO SERRA POR

TRESS A UM. / E O LINHARES

TAMBÉM VENCEU O

RIACHUELO, PELO MESMO

PLACAR. / . AGORA, À NOITE,

TEM MAIS QUATRO

JOGOS. / . CONFIRA A

TABELA. / / /

\section{/ / / / / / RODA VT / / / / / / /}

No enunciado, depois de fazer um breve apanhado do campeonato de futebol do Estado do Espírito Santo, o enunciador, mais do que dar uma ordem, mesmo o verbo estando na terceira pessoa do singular do imperativo (você), faz um convite ao telespectador para que confira os jogos da noite e, assim, sabendo que vão acontecer assista a eles ou não.

O enunciador procura exercer certos efeitos sobre interlocutor, dando-lhe ordens, sugerindo procedimentos, lembrando-o de futuros acontecimentos, etc. No entanto, os efeitos podem se realizar ou não. Um ato de ameaça pode não persuadir o interlocutor; um ato de ameaça, necessariamente, não precisa resultar numa ação.

\section{A audiência presentificada}

Operadores de leitura: o telejornal se vale de uma série de operações para dar instruções ao telespectador (co-enunciador) sobre os procedimentos para sua a leitura, isto é, as formas de lê-lo e percebê-lo. Nesse sentido, todo noticiário é um modelo enciclopédico, um manual de instruções, isto é, programa seu telespectador.

O texto de um telejornal é como um espaço imaginário onde são propostos múltiplos espaços de participação à audiência; uma paisagem, de qualquer maneira, onde a audiência pode escolher o seu caminho com mais ou menos liberdade. Espaço onde há zonas nas quais o telespectador (co-enunciador) se arrisca a se perder ou, ao contrário, aportar em um cais tranqüilo. Essa paisagem é, mais ou menos, plana, mais ou menos, contrastada. Ao longo de todo o seu caminho, a audiência encontra atalhos, trilhas e personagens diversos com os quais procura ou não estabelecer uma relação, segundo a imagem que lhe é oferecida, o modo pelo que é tratada ou a intimidade que lhe é proposta.

O texto jornalístico é um espaço habitado, pleno de decorações e de objetos: ler é pôr em movimento esse universo, aceitando-o ou recusando-o, indo à direita ou à esquerda, investindo mais ou menos esforço, fingindo escutar ou escutando. Dentro dessa perspectiva, tentamos investigar os traços, os operadores, que convidam a au- 
diência a preencher estes espaços vazios, por exemplo, as elipses. Exemplo:

-VIVO EXTERNA- greve/ônibus noite 29/05/2000

(E16) Loc./apres. :

BOA-NOITE.

SEGUNDA-FEIRA DE

PROTESTOS E SURPRESAS. / A

GREVE DOS MOTORISTAS DE

ÔNIBUS, INICIADA HOJE DE

MANHÃ, CONTINUA NA

GRANDE VITÓRIA. / O

PROTESTO É CONTRA A

SUSPENSÃO DO PASSE

LIVRE. / O REPÓRTER ANDRÉ

JUNQUEIRA ESTÁ NO CENTRO

DE VITÓRIA E MOSTRA COMO

OS TRABALHADORES ESTÃO

FAZENDO PARA TENTAR

VOLTAR PARA CASA./ / /

/ / / / / / VIVO EXTERNA / / / / / / /

No enunciado sentimos a falta do artigo indefinido uma. Com acréscimo do artigo teríamos: Uma segunda-feira de protestos e surpresas. Esse é um recurso enunciativo muito utilizado no jornalismo, o uso de uma figura de supressão, a elipse, que consiste em suprimir termos necessários à construção do enunciado, mas indispensáveis à compreensão do sentido.

Verificamos que o enunciador propõe uma instrução, uma espécie de senha e uma questão como um caminho a ser percorrido pela a audiência. $\mathrm{O}$ enunciado funciona, como um roteiro, um script a ser preenchido.

Como num jogo, é oferecida à audiência a possibilidade de entrar na partida com o investimento dos seus mecanismos de projeção e identificação com aquilo que se dá como objeto ofertado. É nessa relação que se estabelecem vínculos, cumplicidades.

\section{A funçã॰ didática do jornalism॰}

Os operadores didáticos: os jornalistas, de uma maneira geral, têm uma preocupação didática com relação à audiência. Isso é cons- truído desde os tempos da universidade até o dia-a-dia da redação. No que diz respeito ao mundo acadêmico, o livro de Paternostro: O Texto na TV : Manual de Telejornalismo, adotado pela maioria dos cursos de jornalismo do Brasil, é um exemplo disso.

No capítulo que trata do texto coloquial, a autora diz que a tevê tem a obrigação de respeitar o telespectador e transmitir a informação em uma linguagem coloquial e correta. Ela explica que quem assiste ao telejornal só ouve o texto uma vez, por isso deve ser capaz de captá-lo, processá-lo e retê-lo instantaneamente. Não há uma segunda chance.

Se o telespectador se desligar, não há desculpas: o erro foi nosso. Quanto mais as palavras (ou o texto como um todo) forem 'familiares' ao telespectador, maior será o grau de comunicação. As palavras e as estruturas das frases devem estar o mais próximo possível de uma conversa. Devemos usar palavras simples e fortes, elegantes e bonitas, apropriadas ao significado e à circunstância da história que queremos contar (PATERNOSTRO, 1999, p.78-85).

O Manual de Telejornalismo da Rede Globo assume um ar professoral ao explicar como o telespectador, a audiência deve ser tratada:

Um dos grandes desafios do telejornalismo é a 'tradução' de informações técnicas, a apresentação de pacotes econômicos, a decifração de termos financeiros, etc. Tanto o repórter - na hora de colher as informações - como o redator, na hora de escrever o off , a cabeça da matéria deve ser humilde o suficiente para perguntar, pesquisar e simplificar (...) É preferível sermos tachados de professorais por uma elite de escolarização a não sermos entendidos por uma massa enorme de teles-pectadores comuns (MANUAL DA GLOBO 
DE TELEJORNALISMO, Central Globo de Jornalismo, 1986, p.23-24).

Exemplo:

- farmácias/genéricos 16/06/2000

(E22) Loc./apres. :

MAIS UM INSTRUMENTO A

FAVOR DA SAÚDE DO

CONSUMIDOR. / A PARTIR DE

AMANHÃ, A FARMÁCIA QUE

NÃO TIVER A LISTA DE

GENÉRICOS À MOSTRA VAI

SER MULTADA. / HOJE,

MUITAS DELAS JÁ ESTAVAM

CUMPRINDO A

DETERMINAÇÃO. / MAS O

CONSUMIDOR AINDA

CONTINUA ENCONTRANDO UMA

DIFICULDADE: ENCONTRAR O

GENÉRICO DESEJADO. / / /

\section{/ / / / / / RODA VT / / / / / / /}

O enunciador anuncia que há mais um instrumento a favor da saúde do consumidor. A situação permite inferir que já existiam outros instrumentos que beneficiavam o consumidor. Além disso, ainda no enunciado, ao utilizar a partir de amanhã, cuidemse as farmácias, quem não tiver remédios genéricos nas prateleiras vai ser multado. No entanto, utilizando-se de uma estratégia argumentativa, contrapondo o hoje ao amanhã o enunciador diz que muitas delas não possuíam os genéricos.

$\mathrm{O}$ argumento é reforçado no enunciado com a ressalva do mas com a ênfase do ainda, indicando que não está sendo fácil para os consumidores comprarem os genéricos nas farmácias porque eles não são encontrados.

Nesse sentido, acreditamos reduzir o fazer jornalístico a uma mera reprodução do real é desconhecer a sua dimensão simbólica. Como podemos ver são tantos os "discursos" - não cometeríamos uma heresia se disséssemos que são infinitos - que atravessam o campo jornalístico, são tantas as tensões, as "vozes", as práticas discursivas, que reduzi-lo a uma simples técnica, ao simples acionamento de regras "mecânicas", seria perder sua própria dimensão, seu próprio objeto. O discurso não é uma das funções entre outras do jornalismo; pelo contrário, ocupa um lugar central na construção social da realidade.

Dentro desse contexto, consideramos que é possível formular a hipótese de que os jornalistas constroem seus textos a partir da cultura profissional, da organização do trabalho, dos processos produtivos, dos códigos particulares (as regras de redação), da língua e das regras do campo das linguagens para, no trabalho da enunciação, produzirem discursos. E o trabalho que os profissionais do jornalismo realizam, ao operar sobre os vários discursos, resulta em construções que, no jargão jornalístico, podem ser chamadas de notícias •

\section{Referências}

AMARAL, L. Técnica de jornal e periódico. 2.ed. Rio de Janeiro: Tempo Brasileiro/MEC, 1987.

AUSTIN, J. L. Quando dizer é fazer: palauras em ação. Porto Alegre: Artes Médicas, 1990.

BAHIA, J. Jornal, história e técnica. 4.ed. São Paulo: Ática, 1990.

BAKHTIN, M. Estética da criação verbal. São Paulo: Martins Fontes, 1992.

BENVENISTE, É. Problemas de lingüística geral I. 4.ed. Campinas: Pontes, 1995.

. Problemas de lingüística geral II. Campinas : Pontes, 1989.

FAUSTO NETO, A. Mortes em derrapagem. Rio de Janeiro: Rio Fundo, 1991.

LOPES, S. A. Sobre o discurso jornalístico. Verdade, legitimidade e identidade. Rio de Janeiro, março de 1990. Dissertação (Mestrado em Comunicação) - Escola de Comunicação da Universidade Federal do Rio de Janeiro.

MACHADO, A. A televisão levada a sério. São Paulo : Editora Senac, 2000. 
MEDITSCH, E. O conhecimento do jornalismo. Florianópolis: UFSC, 1992.

REQUENA, J. G. El espectáculo informativo. Madrid : Akal, 1989.

RODRIGUES, A. D. 0 campo dos media. Lisboa: Vega, 1988.

STAMM, K.R. The nature of news-news concepts. In: McCOMBS, Maxwell; SHAW, Donald Lewis; GREY, David(orgs.) Handbook of reporting methods. Houtghton Mifflin Company: Londres, 1976.

TUCHMAN, G. La producción de la noticia: Estudio sobre la construcción de la realidade. Barcelona: Bosch, 1993.

VIZEU, A. A audiência presumida nas noticiais no caso dos telejornais locais. Rio de Janeiro, outubro de 2002. Tese (Doutorado Comunicação) - Escola de Comunicação da Universidade Federal do Rio de Janeiro. 